\title{
Extension of the diet of an extreme foraging specialist, the aardwolf (Proteles cristata)
}

\author{
J.L. de Vries' ${ }^{1}$, C.W.W. Pirk², P.W. Bateman ${ }^{1,3}$, E.Z.Cameron ${ }^{1, \ddagger}$ \& F. Dalerum ${ }^{1,4^{*}}$ \\ ${ }^{1}$ Mammal Research Institute, Department of Zoology and Entomology, University of Pretoria, \\ Pretoria, 0002 South Africa \\ ${ }^{2}$ Social Insect Research Group, Department of Zoology and Entomology, University of Pretoria, \\ Pretoria, 0002 South Africa \\ ${ }^{3}$ School of Veterinary and Biomedical Sciences, Murdoch University, Murdoch WA 6150, Australia \\ ${ }^{4}$ Centre for Wildlife Management, Hatfield Experimental Farm, University of Pretoria, \\ Pretoria, 0002 South Africa \\ Received 31 January 2011. Accepted 1 April 2011
}

The aardwolf, Proteles cristata, is a highly specialized myrmecophagous carnivore that feeds almost exclusively on termites of the genus Trinervitermes. Here we report data from an ongoing analysis of aardwolf diet, where we documented remains of sun spiders and scorpions in aardwolf scats. Although the prevalence of these items was low, with sun spiders recorded in nine and scorpion remains in one of 246 scats, our observations suggest that aardwolves opportunistically feed on larger prey than previously thought. However, our observations do not suggest that aardwolves utilized these large prey items as alternatives to their main food resource during periods of food scarcity. Therefore, we suggest that the adaptive advantages of such opportunism may be small, but that the observed behavioural plasticity could be advantageous under specific environmental conditions and therefore is maintained as a behavioural trait.

Key words: carnivore, solifugids, diet breadth, resource utilization.

$\mathrm{M}$ ammal dietary strategies range along a gradient from generalist to specialist foragers. Generalists feed on a broad spectrum of dietary items approximately in proportion to their immediate availability (e.g. Reid et al. 1997), while species that exhibit specialized strategies use a restricted part of available food resources, and typically feed on these more than what would be predicted from their relative availability (Anderson \& Erlinge 1977). Therefore, while the adaptive advantages of generalist strategies seem intuitive, the development and maintenance of specialist foraging strategies are puzzling (Abrahams 1987; Abrahams 1999; Fox \& Vasseur 2008).

"Present address: School of Zoology, Hobart Campus, University of Tasmania, Tasmania, Australia

*Author for correspondence.

E-mail: fredrik.dalerum@zoology.up.ac.za
The aardwolf (Proteles cristata) is a small $(5-10 \mathrm{~kg})$ insectivorous hyaenid that is generally regarded as one of the most specialized foragers within the Carnivora (Koehler \& Richardson 1990). There are two subspecies with separate distributional ranges in East and southern Africa. The diet has been quantified for both subspecies (Smithers 1971; Kruuk \& Sands 1972; Cooper \& Skinner 1979; Bothma et al. 1984; Richardson 1987b; Kok \& Hewitt 1990; Taylor \& Skinner 2000; Matsebula et al. 2009), with all studies indicating that aardwolves are extremely specialized and feed almost exclusively on one genus of termite, Trinervitermes, occasionally supplemented with the harvester termite Hodotermes mossambicus in southern Africa (Richardson 1987a). Other taxa of invertebrates that have been recorded in their diet include beetles (Coleoptera), ants (Hymenoptera: Formicidae), and other termite genera such as Odontotermes, Macrotermes and Lepidotermes. (Kruuk \& Sands 1972; Cooper \& Skinner 1979).

Sun spiders (Arachnida: Solifugae) and scorpions (Arachnida: Scorpiones) are commonly found in southern Africa (Dean \& Griffin 1993; Griffin 1998; Leeming 2003), and form part of the diet of many birds and mammals (Arlettaz et al. 1995; Nel \& Kok 1999; Kopij 2002; Kok \& Nel 2004; Kopij 2005; Kopij 2007; Pietersen \& Symes 2010). Sun spiders are not venomous, but they possess strong chelicerae and it has been suggested that they mimic the hiss of adders by stridulating (Hrušková-Martišová et al. 2008), both of which act as a defence mechanism against potential predators. Scorpions in southern Africa vary in venom strength from the highly venomous Parabuthus to weakly-venomed species of Hodogenes. As far as we are aware, there has been only one previous record of sun spiders in 
aardwolf diets (Smithers 1971), and no records of scorpion remains.

Here we present data on rare or unrecorded incidences of sun spiders and scorpions in the diet of aardwolves from central South Africa, and discuss these occurrences in the light of the dietary strategies of this highly specialized forager.

We conducted the study on Benfontein Game Reserve in the Northern Cape Province, South Africa $\left(28^{\circ} 50^{\prime} \mathrm{S}, 24^{\circ} 50^{\prime} \mathrm{E}\right)$, between June 2008 and December 2009. We collected aardwolf scats weekly from middens located within the territories of ten radio-collared aardwolves. Although our study has suggested a substantial home range overlap in aardwolves, most of these ten animals had discrete ranges in relation to each other. We therefore believe that our scat analysis is reflecting the diet of at least 10 animals. Because the area has a distinct seasonal rainfall pattern, we divided each year into a wet and a dry season based on data received from the South African Weather Bureau, and scats were categorized by season. We randomly selected 246 of 521 collected scats, including 128 scats from the wet and 118 scats from the dry season.

We dried scats at $70^{\circ} \mathrm{C}$ for a period of $24 \mathrm{~h}$ and then washed them through a series of sieves to remove excess soil. We analysed washed scats for the presence of arthropod remains, such as termite and ant heads, beetle elytra and any other skeletal remains. To estimate the size of sun spiders and scorpions we measured the length of each sun spider chelicera and scorpion pincer recorded in scats. These were then compared to the same parts from intact specimens collected during a concurrent pitfall survey in the area.

We found remains from the termite Trinervitermes trinervoides in all but one of the 246 scats analysed, supporting the expected dietary specialization of aardwolves within our study population. In addition we found remains of sun spiders in nine of the 246 scats $(3.7 \%)$, and remains of scorpions in one scat $(0.4 \%)$. Two of the scats containing sun spiders were collected during the dry season and seven during the wet season, while the scat containing the scorpion remains was collected during the wet season. The scats were collected from middens in the home ranges of five different aardwolves, suggesting that they may have been deposited by at least five individuals. The length of sun spider chelicerae varied from 3-5 mm, indicating that the individuals consumed were between 20 and $40 \mathrm{~mm}$ in length. The scorpion pincers were $8 \mathrm{~mm}$ long which translates to a scorpion of about $70 \mathrm{~mm}$ in length.

Since both the scorpion and most of the sun spider remains were recorded in the scats from the wet season, which is when termites are most available as prey, our observations suggest that neither sun spiders nor scorpions were utilized as alternative prey during periods of food scarcity, but rather were consumed opportunistically. Since sun spiders are active and can deliver a painful bite (Leeming 2003; Hrušková-Martišová et al. 2008), it seems unlikely that they were ingested accidentally. We identified the scorpion as Opistophthalmus sp. (Scorpionidae). These scorpions are sit-andwait predators (Leeming 2003), similarly suggesting that their consumption was unlikely to be accidental.

Our observations suggest a degree of opportunism in aardwolf foraging behaviour, since both sun spiders and scorpions appear to have been actively preyed upon. Such opportunism can be regarded as adaptive if it helps specialized foragers sustain themselves during periods of food scarcity. However, these large prey items were consumed when the main prey items were most available rendering this explanation unlikely. Alternatively, behavioural plasticity in diet selection may be advantageous to individuals, since using a variety of food items may help individuals survive periods of food shortage, and may also be advantageous at other times, providing extra nutrition during, for example, breeding seasons. We therefore believe that such opportunism may be regarded as latent behavioural plasticity that may only become directly advantageous under specific environmental conditions, but is still retained within the population because it carries low evolutionary costs.

Funding for this study was provided by the National Research Foundation of South Africa in the form of a focal area grant (EZC), the incentive funding programme (FD; CWWP) and from the DST-NRF South African Research Chair Initiative chair of Mammal Behavioural Ecology and Physiology awarded to N.C. Bennett. We are grateful to the De Beers Consolidated Mines Inc. for allowing us to conduct research on Benfontein Game Reserve, and managers and staff that assisted us on the reserve. Numerous people assisted with field data collection and laboratory analyses of scats, and Andrew Davies gave helpful comments on the manuscript and assisted with termite identification. N.C. Bennett gave constructive comments on the manuscript and provided invaluable assistance in facilitating our field research on aardwolves. 


\section{REFERENCES}

ABRAHAMS, P.A. 1987. Alternative models of character displacement and niche shift 1. Adaptive shifts in resource use when there is competition for nutritionally nonsubstitutable resources. Evolution 41: 651-661.

ABRAHAMS, P.A. 1999. The adaptive dynamics of consumer choice. American Naturalist 153: 82-97.

ANDERSSON, M. \& ERLINGE, S. 1977. Influence of predation on rodent populations. Oikos 29: 591-597.

ARLETTAZ, R., DÄNDLIKER, G., KASYBEKOV, E., PILLET, J., RYBIN, S. \& ZIMA, J. 1995. Feeding habits of the long-eared desert bat, Otonycteris hemprichi (Chiroptera: Vespertilionidae). Journal of Mammalogy 76: 873-876.

BOTHMA, J.D.P., NEL, J.A.J. \& MACDONALD, A. 1984. Food niche separation between four sympatric Namib desert carnivores. Journal of Zoology (London) 202: 327-340.

COOPER, R.L. \& SKINNER, J.D. 1979. Importance of termites in the diet of the Proteles cristatus in South Africa. South African Journal of Zoology 14: 5-8.

DEAN, W.R.J. \& GRIFFIN, E. 1993. Seasonal activity patterns and habitats in solifugae (Arachnida) in the southern Karoo, South Africa. South African Journal of Zoology 28: 91-94.

FOX, J.W. \& VASSEUR, D.A. 2008. Character convergence under competition for nutritionally essential resources. American Naturalist 172: 667-680.

GRIFFIN, R.E. 1998. Species richness and biogeography of non-acarine arachnids in Namibia. Biodiversity and Conservation 7: 467-481.

HRUŠKOVÁ-MARTIŠOVÁ, M., PEKÁR, S. \& GROMOV, A. 2008. Analysis of the stridulation in solifuges (Arachnida: Solifugae). Journal of Insect Behaviour 21: 440-449.

KOEHLER, C.E. \& RICHARDSON, P.R.K. 1990. Proteles cristatus. Mammalian Species 363: 1-6.

KOK, O.B. \& HEWITT, P.H. 1990. Bird and mammal predators of the harvester termite Hodotermes mossambicus (Hagen) in semi-arid regions of South Africa. South African Journal of Science 86: 34-39.

KOK, O.B. \& NEL, J. A.J. 2004. Convergence and divergence in prey of sympatric canids and felids: oppor- tunism or phylogenetic constraint? Biological Journal of the Linnean Society 83: 527-538.

KOPIJ, G. 2002. Food of the lesser kestrel (Falco naumanni) in its winter quaters in South Africa. Journal of Raptor Research 36: 148-152.

KOPIJ, G. 2005. Diet of some insectivorous passerines in semi-arid regions of South Africa. Ostrich. 76: 85-90.

KOPIJ, G. 2007. Seasonal and annual dietary changes in lesser kestrels Falco naumanni wintering in Lesotho. Ostrich 78: 615-619.

KRUUK, H. \& SANDS, W.A. 1972. The aardwolf (Proteles cristatus Sparrman 1783) as a predator of termites. East African Wildlife Journal 10: 211-227.

LEEMING, J. 2003. Scorpions of Southern Africa. Struik Publishers, Cape Town.

MATSEBULA, S.N., MONADJEM, A., ROQUES, K.G. \& GARCELON, D.K. 2009. The diet of the aardwolf, Proteles cristatus at Malolotja Nature Reserve, western Swaziland. African Journal of Ecology 47: 448-451.

NEL, J.A.J. \& KOK, O.B. 1999. Diet and foraging group size in the yellow mongoose: a comparison with the suricate and the bat-eared fox. Ethology Ecology $\mathcal{E}$ Evolution 11: 25-34.

PIETERSEN, D.W. \& SYMES, G.T. 2010. Assessing the diet of Amur Falcon Falco amurensis and lesser kestrel Falco naumanni using stomach content analysis. Ostrich 81: $39-44$.

RICHARDSON, P.R.K. 1987a. Aardwolf: the most specialized myrmecophagous mammal? South African Journal of Science 83: 643-646.

RICHARDSON, P.R.K. 1987b. Food-consumption and seasonal variation in the diet of the aardwolf Proteles cristatus in southern Africa. Zeitschrift für Saugetierkunde 52: 307-325.

REID, D.G., KREBS, C.J. \& KENNEY, A.J. 1997. Patterns of predation on noncyclic lemmings. Ecological Monographs 67: 89-108.

SMITHERS, R.H.N. 1971. The Mammals of Botswana. National Museum of Rhodesia, Bulawayo, Zimbabwe.

TAYLOR, W.A., SKINNER, J.D. 2000. Associative feeding between aardwolves (Proteles cristatus) and aardvarks (Orycteropus afer). Mammal Review 30(2): 141-143.

Responsible Editor: J.H. van Wyk 